\title{
Direitos humanos em balanço: enquadramentos teóricos e recortes empíricos
}

(D) Mariana Thorstensen Possas'

Orcid: https://orcid.org/0000-0003-2201-860X

(1) Caroline Caldas"

Orcid: https://orcid.org/0000-0001-5464-490X

(D) Núbia dos Reis Ramos"II

Orcid: https://orcid.org/0000-0002-1433-1981

(D) Maíne Souzalv

Orcid: https://orcid.org/0000-0002-6594-9116

DOl: 10.17666/bib9703/2022
Submetido em 02/02/2022

Aceito em: 03/02/2022

\section{Introdução}

Propomos neste texto apresentar um balanço bibliográfico do campo temático dos direitos humanos na última década (2011-2021), analisando trabalhos e pesquisas produzidos nas ciências sociais brasileiras e na literatura internacional de língua inglesa, em especial os produzidos no Canadá e nos EUA. Mais especificamente, nossa seleção reuniu trabalhos que apresentaram uma abordagem socio-histórica dos direitos humanos, que os enquadra como objeto das ciências sociais e/ou da história e que propõem algum tipo de problematização do próprio conceito ou categoria. Isso significa excluir a maior parte dos trabalhos acadêmicos produzidos sobre o tema, com abordagens exclusivamente jurídicas ou de conteúdo político-filosófico. Excluímos também os trabalhos que se

\footnotetext{
'Professora de Sociologia da Universidade Federal da Bahia (UFBA). E-mail: marianapossas@ gmail.com.

" Doutora em Ciência Política (PPGCP/UFF) e Pesquisadora de pós-doutoradno no PPGCS/ UFBA.carolsac@gmail.com.

I'" Doutoranda do Programa de Pós-Graduação de Ciências Sociais, Universidade Federal da Bahia (UFBA) e Professora Assistente da Universidade do Estado da Bahia (UNEB). E-mail: nubiaramos.ciso@gmail.com.

Iv Mestranda do Programa de Pós Graduação em Ciências Sociais da UFBA. mainesouza@ufba.br. Publicado em: março de 2022 | pp. 1-21
} 
propunham a apenas descrever a estrutura política e jurídica internacional de direitos humanos, assim como de seu funcionamento burocrático.

Além de nomearem leis, tratados e tribunais internacionais ${ }^{1}$, os direitos humanos se construíram nas últimas cinco décadas como uma realidade comunicacional de relevância no mundo ocidental. Ainda que normalmente associada ao direito (Clément, 2018), a realidade social dos direitos humanos manifesta-se empiricamente em práticas e discursos cotidianos de várias ordens (política, jurídica, científica, educacional, religiosa etc).

Partimos da constatação histórica sugerida por Moyn (2010) em relação aos Estados Unidos e Inglaterra e por Clément (2018) no Canadá, de que os direitos humanos entram nas comunicações cotidianas sobretudo a partir dos anos 1970, quando finalmente se tornam uma referência comum e se transformam em uma ferramenta política (comunicacional) amplamente utilizada. Em pesquisa nos jornais New York Times e The Guardian, Moyn (2010) observa que a expressão começa a ser usada nos jornais especialmente a partir dos anos 1970, a despeito da instituição do sistema internacional de direitos humanos datar do final dos anos 1940 . A mesma observação Clément (2018) realizou no Canadá, ao analisar os jornais Globe and Mail, Toronto Star e Winnipeg Free Press. Em pesquisa semelhante exploratória no Brasil, verificamos os acervos dos jornais $O$ Estado de S. Paulo e Folha de S. Paulo e observamos aumento expressivo de matérias indicando o termo direitos humanos na década de $1970^{2}$.

Ao mesmo tempo em que emergem e se fortalecem no imaginário político (López, 2018) nas décadas seguintes, um movimento de oposição e resistência aos direitos humanos foi-se constituindo, o que chamamos em outro texto (Possas et al, 2020) ${ }^{3}$ de movimento de desconstrução dos direitos humanos. Esse movimento culmina na eleição federal de 2018, quando se elege um governo com uma agenda e um discurso explicitamente anti-direitos humanos. (Machado, 2020; Silva, 2020).

Assim como observado em outros países, o Brasil também possui uma lacuna na literatura sócio-historiográfica dos direitos humanos, considerando que a maior parte dos trabalhos dedicados a historiar os direitos humanos produzem o que Moyn (2010) chama de "história evolutiva", linear e cumulativa, em que a descrição do processo histórico se confunde com a valorização de suas justificativas. Embora acolha variação de recortes e abordagens, o caráter normativo é uma característica comum dessa literatura (Moyn, 2010; Clément, 2018; López, 2018), apoiada num diálogo profundo com o pensamento iluminista. Hunt (2007) nos EUA, Bobbio (2004) na Europa e Comparato (2010) no Brasil, ao apresentarem

\footnotetext{
${ }^{1}$ As normas legais que fazem parte do que Ignatieff chama de "revolução jurídica dos direitos humanos" são: a Carta da ONU de 1945, a Declaração Universal dos Direitos Humanos da ONU, de 1948, a Convenção de Genocídio de 1948, as Convenções de Genebra e 1949 e a Convenção de Refugiados de 1951. (IGNATIEFF, 2001: 7)

2 Em pesquisa realizada, no ano de 2020, nos acervos dos jornais Folha de S. Paulo e Estado de S. Paulo, na década de 1960 há 1638 e 751 menções, respectivamente. Em 1970 os números saltaram para 5947 e 4578. (Acervo Folha; Acervo Estadão - O Estado de S. Paulo).

3 Projeto de pesquisa "História dos Direitos Humanos no Brasil", desenvolvido entre o LASSOS/ UFBA, NEV/USP, IESP/UERJ. Propomos neste projeto a construção de uma história de mão dupla de construção e desconstrução de direitos humanos a partir dos anos 1970 até 2020 (POSSAS et al, 2020).
} 
suas versões de uma história dos direitos humanos no Ocidente, são exemplos desse tipo de enquadramento evolutivo. A literatura brasileira segue, grosso modo, essa orientação, ainda que pudéssemos contar com autores, sobretudo da antropologia, que analisaram os direitos humanos sob uma ótica não exclusivamente normativa (Sousa 2001; Ribeiro, 2003).

Reconhecemos que a vasta literatura jurídico-filosófica referente aos direitos humanos é em parte consequência direta do desenvolvimento legal em âmbito internacional e nacional, com a ampliação de leis designadas para sua proteção. Nossa proposta, na mesma linha de alguns autores contemporâneos, é avançar a discussão sobre o pressuposto da normatividade jurídica e filosófica dos direitos humanos como auto evidente ou auto-explicativa (López, 2018). Do ponto de vista analítico, essa literatura acaba caindo numa armadilha interpretativa e associa muito rápido os avanços da proteção dos direitos humanos às leis, sem considerar outras dinâmicas sociais presentes. Como regra, toma o ideal moral embutido na codificação legal dos direitos humanos como universal e cuja tradução ou interpretação se dá exclusivamente na/pela linguagem ou gramática jurídica (objetiva, neutra e não política), negligenciando a agência humana que a precede (Meckled-García e Çali, 2005; Woodiwiss, 2005b).

Este é o primeiro dos dois grandes desafios de estudar os direitos humanos na perspectiva das ciências sociais no Brasil. Apesar de se auto-caracterizarem como trabalhos de caráter histórico, a grande maioria dos textos tem um forte caráter normativo (jurídico-político-filosófico) que dificulta a compreensão do fenômeno sócio-histórico num sentido mais amplo. O segundo desafio é a enorme variedade de situações-problema que são enquadradas no grande guarda-chuva do imaginário político dos direitos humanos, incluindo desde situações concretas (combate à violências físicas) a lutas e categorias abstratas (dignidade humana).

Buscando enfrentar minimamente o primeiro desafio, excluímos deste balanço os textos jurídico-normativos, assim como aqueles que propõem uma reflexão exclusivamente filosófica a partir do conceito ou da ideia de direitos humanos. Em relação aos segundo desafio, mesmo de forma não exaustiva, nos propusemos a focar em textos que tematizam em alguma medida o próprio conceito de direitos humanos. O mesmo exercício restritivo valeu para os textos em inglês. Em nosso critério, selecionamos aqueles trabalhos que não apenas mencionam ou fazem referência aos direitos humanos, mas que mobilizam algum tipo de problematização do próprio uso dos direitos humanos nas práticas e discursos cotidianos.

\section{Os direitos humanos como categoria das ciências sociais no Brasil e na América do Norte}

$\mathrm{Na}$ revisão de textos de língua inglesa nos concentramos na produção norteamericana, sem excluir autores de outras origens ${ }^{4}$. A América do Norte, especialmente Canadá e Estados Unidos, tem uma importante produção em língua inglesa sobre o tema dos direitos humanos, tanto a partir das ciências humanas, incluindo aqui história, sociologia, ciência política, antropologia, relações internacionais, como do direito. Além da importância da produção acadêmica na área, o foco na

\footnotetext{
4 Sjoberg et al (2001), da Suiça, Madsen e Verschraegen (2013) da Bélgica e Dinamarca, Hopgood (2013) Inglaterra, entre outros.
} 
literatura produzida nesses dois países se justifica pelos intercâmbios construídos recentemente com autores canadenses e norte-americanos na realização do projeto de pesquisa mencionado acima (Possas et al., 2020) que tem nos ajudado a construir compreensões mais profundas sobre os argumentos em questão.

Essa literatura internacional inglesa $\mathbf{5}^{\mathbf{5}}$ apresenta reflexões que datam da primeira década do século XX e que funcionam como precursores da literatura mais recente que identificamos como mais crítica. Autores como Sjoberg et al (2001), Blau e Moncada (2005) Turner (2006) já vislumbravam a emergência de uma sociologia dos direitos humanos, ainda pouco consolidada mas necessária para compreender os fenômenos sociopolíticos contemporâneos no mundo ocidental.

Morgan (2009), Morris (2006); Turner (1993) e Woodiwiss (2005a) reconhecem a sociologia dos direitos humanos como um subcampo emergente, mas com uma agenda de pesquisa menos robusta em relação à ciência política, às relações internacionais e à antropologia. Seu desenvolvimento tardio é explicado por três obstáculos: a pouca centralidade que os direitos humanos assumiram na tradição sociológica clássica (Marx, Weber e Durkheim); substituição dos direitos humanos pelo tema da cidadania; e a dificuldade em conceituar o que são direitos humanos. (Somers e Roberts, 2008; Morgan, 2009).

No Brasil, referências importantes que antecedem a década atual também foram fundamentais para compreender os caminhos tomados pelos autores que os sucederam. Do ponto de vista da ciência política, Pinheiro (1991), propõe uma das primeiras reflexões a partir das ciências sociais sobre o tema, ao tratar do processo de transição democrática do Brasil diante da nossa cultura autoritária. Na sociologia, Adorno (2000) e Caldeira (2000) destacam a forma não-linear com que os direitos humanos foram institucionalizados no Brasil no contexto da redemocratização.

A experiência de violência na década de 1980 teve um impacto significativo em como a noção de direitos humanos foi absorvida socialmente e a "fala do crime" (Caldeira, 2000) foi se construindo em contraposição à sua defesa. Singer (2003), em uma perspectiva crítica em relação aos direitos humanos, reitera a importância do fenômeno da violência para a construção do campo no Brasil. Sugere que há um desconcerto nos discursos que se dizem favoráveis aos direitos humanos, na medida em que muitos aderem a uma demanda por punição criminal (com pena de prisão) como solução dos problemas e violências apontados por eles.

\section{Literatura conceitual internacional de língua inglesa (2011-2021)}

São raros na história intelectual conceitos que despertam o interesse em áreas disciplinares tão diversas quanto o direito, a filosofia, a história e os estudos culturais, como aconteceu com os direitos humanos nas últimas duas décadas (Benhabib, 2013, p. 81). Recentemente assistimos a emergência de uma nova historiografia crítica que põe em questão a crônica amplamente aceita das origens e do desenvolvimento dos direitos humanos. O representante dessa produção é o historiador Samuel Moyn (2010, 2014, 2015, 2018, 2020). Na sociologia, uma

\footnotetext{
5 É importante mencionar a condição particular dos Estados Unidos e de sua relação com os direitos humanos Para os norte-americanos, direitos humanos é um assunto de política internacional e não servem para embasar lutas por direitos em âmbito doméstico (Ignatieff, 2001; Moyn, 2018; López, 2018). Existe uma enorme resistência dos EUA em assinar os tratados internacionais de direitos humanos e de aplicar suas normas para os cidadãos ou instituições americanas. Isso resulta numa situação paradoxal, por ao mesmo tempo promover os direitos humanos ao redor do mundo e resistir sua aplicação em território nacional (2001, p. 13).
} 
linhagem relativamente nova de estudos sobre os direitos humanos abraçam o desafio de pensar os direitos de uma perspectiva sócio-histórica: Hynes et al (2011); Woodiwiss (2005a e 2005b); Joas (2012); Madsen e Verschraegen (2013); Hopgood (2013 e 2014); Frezzo (2015); Clément (2017 e 2018); e López (2018).

No final da década passada, Moyn (2010) propôs uma história dos direitos humanos que, ao invés de evolutiva e progressiva, é cheia de rupturas, descontinuidades e quebras inesperadas (Benhabib, 2013). Na contramão de uma história de origem remota, observa que somente após os anos 1970 a ideia de "direitos humanos", tal como a concebemos hoje, está em circulação, apropriada pelos movimentos sociais e instalada na linguagem comum das reivindicações políticas e eventualmente jurídicas. Entre a data de promulgação da Declaração Universal dos Direitos do Homem (1948) e os anos 1970, vivemos em um período em que os direitos humanos permaneceram periféricos enquanto um conceito organizador, e quase inexistentes como movimento socialmente relevante (Moyn, 2010, p. 2).

Acompanhada dessa nova forma abordagem, há uma série de críticas possíveis à construção histórica de Moyn (Benhabib, 2013; Roriz, 2018), que, entre outras muitas proposições provocadoras, estabelece a distinção histórica de categorias "direitos do homem", "direitos do cidadão" ou apenas "direitos", sem tratá-las como sinônimos ou equivalentes necessários de "direitos humanos". Essa maneira de observar as comunicações, localizando historicamente os usos das expressões e as demandas formuladas em seu nome, implica o desmembramento dessas categorias da referência filosófica para associá-las a eventos históricos e, como consequência, produz uma redução do escopo do conceito.

Por outro lado, esse movimento permite compreender a trajetória que essa utopia (Moyn, 2010), ou esse imaginário político (López, 2018), assumiu nas últimas décadas, em especial da euforia dos anos 1990 aos atuais movimentos de resistência dos anos 2010. Dentre as indicações que os sociólogos podem tirar dessa nova historiografia crítica passam pela constatação de que "existem demasiadas suposições não examinadas sobre o que são os direitos humanos, de onde vêm, como se deslocam social e historicamente e a natureza da sua eficácia social" (López, 2018, p.48, tradução nossa). No fundo, ainda estamos aprendendo a (re)conhecer a realidade social dos direitos humanos. Neste sentido, vamos expor as ideias de alguns autores parecem contribuir para o campo a partir de diferentes olhares e enquadramentos teóricos.

Para Madsen e Verschraegen a sociologia dos direitos humanos pode ser uma ferramenta para "lançar luz sobre por que e como os direitos humanos emergiram como um produto social chave e uma força social na sociedade contemporânea" (2013 p.4, tradução nossa). Hopgood (2013), um dos autores centrais no debate sobre a crise do regime global dos direitos humanos, reflete a partir da perspectiva da linguagem e de suas diferentes possibilidades de formatação e comunicação. Ele se concentra sobre o enfraquecimento dos direitos humanos enquanto sistema internacional e questiona se a linguagem ainda é eficaz para promover mudanças sociais (Hopgood, 2014).

Olhando especificamente para a experiência canadense, Clément $(2017,2018)$ identifica, desde os anos 1970, uma linguagem (vernáculo) dos direitos humanos compartilhada e operada para enquadrar tudo aquilo que se interpreta como injustiça. A partir dessa constatação se pergunta: quais são as consequências desse estado de inflação de direitos? Em outras palavras, quais as "implicações 
de deixar de distinguir entre os direitos humanos, que deveriam ser a mais alta reivindicação possível sobre nossa sociedade, e qualquer reclamação que consideremos uma injustiça?" (Clément, 2018, p.2, tradução nossa). Para o autor, a fala dos direitos (the rights talk) mudou muito na história recente, tornando-se uma fala adaptável aos mais diversos tipos de demandas por justiça. Como consequência dessa mudança, o Canadá observa hoje um fenômeno importante de inflação de direitos, o que não é necessariamente problemático. O problema apareceria quando se torna comum enquadrar toda e qualquer queixa como uma violação de direitos humanos. Sobretudo considerando a baixa capacidade do direito em se tornar veículo de uma mudança social efetivamente transformativa (2018:9 e ss).

Frezzo (2015) e López (2018) apresentam ferramentas teóricas e empíricas para o estudo dos direitos humanos na sociologia. Para Frezzo (2015) a linguagem dos direitos pode ser investigada a partir dos contextos em que são identificados como reivindicações que perpassam as agendas dos movimentos sociais, das esferas de implementação política até a consolidação de um pacote de direitos (rights bundle). López (2018), por sua vez, se propõe a descrever os direitos humanos como um imaginário político, englobando quatro dimensões: da representação discursiva, da tecnologia social, da agência e subjetividade e das formas ou estruturas organizacionais.

\section{Literatura conceitual no Brasil (2011-2021)}

No Brasil, alguns poucos trabalhos produzidos durante a última década propuseram a problematização do conceito de direitos humanos a partir de recortes distintos. Um exemplo é a coletânea de textos ${ }^{6}$ publicada no fim de 2010 pela Secretaria Nacional de Direitos Humanos. Ela levou em conta uma pesquisa de opinião pública que o governo federal teria feito sobre a pluralidade de sentidos atribuídos aos direitos humanos pelos brasileiros. De acordo com Venturi (2010), a hipótese inicial, de que a percepção da maioria da opinião pública seria resistente aos direitos humanos por associá-los diretamente à proteção de bandidos, não foi confirmada.

Outro exemplo de pesquisa sobre o conceito dos direitos humanos a partir da teoria do direito é proposta por Magalhães (2013). Para a autora, o estudo dos direitos humanos deve parar de evitar os paradoxos dos quais pretende fugir e assumir a natureza paradoxal de seu objeto, o que significa incorporar a ideia de que não se capta os direitos humanos a não ser através da reivindicação de sua violação: "das diversas versões do paradoxo dos direitos humanos é, hoje, possivelmente a forma mais radical de se 'levar a sério' esses direitos" (Magalhães, 2013, p. 4).

Na ciência política, Astolfi e Lagatta (2015) analisaram o conceito de graves violações de direitos humanos nos julgamentos do Supremo Tribunal Federal (STF) no período de 2005 a 2014. Observou-se que nos julgamentos de deslocamento de competência, a tomada de decisão pelos julgadores é prejudicada pela imprecisão e contradições contidas nas diversas definições sobre graves violações de direitos humanos, tornando o conceito operacionalmente subjetivo, discricionário e auto-explicativo.

6 Direitos Humanos: percepções da opinião pública (Venturi, 2010) 
Da perspectiva da antropologia, Schritzmeyer (2018) e Eilbaum, Chagas e Medeiros (2020) propuseram uma discussão sobre a definição de humanidade, conceito-chave para o campo dos direitos humanos. As dificuldades, os impasses e os preconceitos mobilizados diante das várias maneiras de conceber a natureza humana produzem um efeito na própria disciplina que estabelece uma relação necessariamente crítica em relação aos direitos humanos.

A discussão sobre os limites do universalismo (das normas internacionais) versus o relativismo (das culturas) é, talvez, uma das contribuições mais relevantes da antropologia, incorporando a dimensão paradoxal sobre os direitos humanos (Eilbaum, Chagas, Medeiros (2020). É próprio da antropologia lembra Schritzmayer (2018) explicitar as origens histórico-ideológicas do universalismo desses direitos, assim como apontar que estes não se realizaram plenamente devido às suas limitações etnocêntricas. Como resultado, a antropologia instaura um respeito relativista por todo e qualquer arranjo cultural, o que não necessariamente limita a adesão aos direitos humanos como estratégia de construção de convergências.

Em uma perspectiva mais sociológica, Possas $(2012,2016)$ propõe uma discussão sobre as possibilidades de enquadramento teórico disponíveis para pensar os direitos humanos, como os conceitos de frame e master frame e, especialmente, a distinção medium/forma, proposta pelo sociólogo Niklas Luhmann. Em Possas et al. (2018), as autoras discutem as categorias usadas para pensar os direitos humanos mobilizados pelas organizações de direitos humanos e pelas cortes internacionais de direitos humanos.

\section{Segundo desafio: diversidade dos potenciais tipos de violação de direitos humanos no Brasil}

Nesta terceira parte, vamos enfrentar o desafio de examinar a infinidade de pautas e reivindicações que podemos caracterizar como violação de direitos humanos no Brasil. Nas últimas décadas, observamos uma pluralidade de temas enquadrados no "guarda chuva" dos direitos humanos. Assim como Clément (2018) caracterizou o fenômeno da inflação dos direitos humanos no Canadá, podemos emprestar a definição para caracterizar o intenso movimento de incorporação de novos direitos, ou de reinterpretação de direitos já existentes, no Brasil.

A produção de estudos na área da sociologia dos direitos humanos pode ser organizada em duas grandes tendências: estudos de problemas sociais caracterizados como violações de direitos humanos e pesquisas sobre a implementação dos direitos por meio das ações e políticas públicas (López, 2018). Nessa primeira tendência, que é a mais comum entre os estudos, os direitos humanos são apresentados como "lugar garantido (taken-for-granted placeholder) de uma idéia abstrata e descontextualizada de justiça e equidade" (p.175), sem problematizar a categoria. Na segunda tendência, o foco reside nos possíveis obstáculos sociais para a efetivação desses direitos. Os textos partem da premissa de que, uma vez superados os obstáculos, os direitos humanos poderiam oferecer uma resposta mais efetiva aos problemas concretos. 
Em nossa coleta dos trabalhos sobre direitos humanos produzidos no Brasil7, observamos as duas tendências mencionadas no campo da ciências sociais. Em muitos textos há referência aos direitos humanos como norma legalizada, seja de tratados internacionais ou nacionais. Grosso modo, os direitos humanos são comumente reivindicados para respaldar um argumento na lei, seja de um direito não respeitado ou um direito reivindicado. Desta forma, fizemos um esforço em distinguir os textos que tratavam de uma ideia/discurso de direito humanos, ou seja, abstrata, descontextualizada (López, 2018) dos textos que tratam de algum problema ou violação concreta de direitos humanos ou de uma história dos direitos humanos.

Dentre essa variedade, selecionamos alguns dos temas que nos pareceram mais centrais para a composição do campo de estudos brasileiros, novamente sem nenhuma pretensão de exaustividade. Ao contrário, procuramos ilustrar a diversidade de um campo sem contornos temáticos definidos. Para além desses recortes, existem muitas outras situações-problema que são construídas e associadas aos direitos humanos em diferentes níveis de familiaridade. Os chamados grupos vulneráveis e suas lutas/demandas políticas são também caracterizados como uma questão de direitos humanos. A luta das mulheres pelo direito de decidir sobre o aborto é um dos temas relevantes dessa linhagem de trabalhos (Santos, 2017); assim como a luta dos grupos indígenas contra as crescentes violências cometidas contra suas populações (Rosa, 2016). Em relação à temática etnico/ racial, Pires (2018), Dávila (2018) e Achiume (2010), pontuam a necessidade de "racializar", "pautar a agenda" e "incluir os afrodescendentes como sujeito de direitos" nos debates sobre direitos humanos.

\section{Política e Justiça de Transição}

A ditadura civil-militar (1964-1985) e suas várias expressões de violência de Estado, assim como o controverso processo de transição democrática, são os primeiros grandes temas brasileiros diretamente associados aos direitos humanos. Alguns trabalhos produzidos na última década focam aspectos específicos dessa discussão, como a história dos direitos humanos no Brasil através da atuação dos bispos da Igreja Católica (Silva, 2017); o surgimento e a inserção dos movimentos de familiares de mortos e desaparecidos políticos nos debates públicos sobre a ditadura no Brasil de 1964 a 1985 (Azevedo, 2016); as Comissões da Verdade no Brasil e suas contribuições para o processo democrático e o reconhecimento do fato histórico, memória e verdade (Almada, 2021), Holanda e Israel (2020), Barros (2020), Holanda (2018); Pinheiro (2018), (Almeida, 2018), Lafer (2014); Pereira (2013); Mezarobba (2010).

Outros trabalhos se debruçam sobre a a justiça de transição, como por exemplo Caldas (2016 e 2021) que analisa as medidas de verdade e justiça no Brasil e o processo de judicialização criminal em nome dos direitos humanos; Sandoval \& Veçoso (2017), Simoni (2016), Bernardi (2016), Schallenmüller (2015), Abrão e

\footnotetext{
${ }^{7}$ Nos textos brasileiros, nos concentramos em livros, artigos, teses e dissertações. As buscas ocorreram no 1) Scielo e Google Acadêmico; 2) Repositório de teses e dissertações da CAPES nas seguintes universidades: USP, UFRJ, UFPE, UNB, UFRGS e UFPB..; 3) Revistas de direitos humanos como SUR, revista UNESP, Coletâneas de Antropologia e Direitos Humanos da ABA, Coletâneas da ANDHEP e SUR Nessa seleção excluímos textos jurídicos ou textos exclusivamente descritivos, assim como como os textos de Educação em Direitos Humanos, que consideramos uma área à parte.
} 
Torelly (2014), Meyer (2014) e Silva Filho (2014) analisam a justiça de transição no Brasil a partir das transformações e disputas dos significados e sentidos do conceito de anistia (legal e política) no Sistema Interamericano e na Comissão de Anistia no Brasil.

Com um olhar voltado para Sistema Interamericano de Direitos Humanos (SIDH), trabalhos como os de Ramanzini (2018), Engstrom (2017); Piovesan e Soares (2016); Wojciechowski (2014); Cardia, et al. (2014) e Bernardes (2011) buscam compreender os impactos do Sistema Internacional de Direitos Humanos na implementação de decisões e no processo de justiça de transição no Brasil. Por sua vez, Guedes, Schäfer, Lara (2020), Cavallo (2018) e Rios et al. (2017) analisam os impactos judiciais desse sistema internacional no Brasil, com especial foco na proteção dos direitos humanos de grupos vulnerabilizados.

\section{Política de segurança pública}

No Brasil, a associação dos direitos humanos a temas da segurança pública é uma consequência do engajamento histórico de movimentos de direitos humanos na luta por direitos dos prisioneiros políticos e, posteriormente, na defesa dos presos comuns. No que concerne ao sistema punitivo, espaço de tensão latente quando se trata de questões relacionados aos direitos humanos, destacamos os trabalhos de Alvarez, Salla e Dias (2013), Ferreira (2019) e Higa e Alvarez (2019). Lemos (2020), por sua vez, analisa a disputa narrativa a partir de um estabelecimento prisional do Distrito Federal. Em relação à polícia, França (2012) e Nascimento (2019) analisam a inserção dos direitos humanos nos cursos de formação de policiais e Eilbaum e Medeiros (2015) discutem a variação sentido atribuída à violência policial, como um problema de direito humanos, nas manifestações de 2013 no Rio de Janeiro.

\section{Políticas públicas de direitos humanos}

Todos os governos do perío do da pós-democratização, de algum modo, promoveram a incorporação dos direitos humanos nas políticas governamentais (Adorno, 2010). Com o novo texto constitucional (1988) e durante a década de 1990, os direitos humanos receberam status de "política de Estado" (Engelmann e Madeira, 2015) e desempenham papel central na política democrática (Koerner, 2003). Em 1996, foi criado o I Programa Nacional de Direitos Humanos no Brasil (PNDH). Nos dois últimos decênios, houve um significativo incremento da institucionalidade dos direitos humanos no país, com a ampliação do PNDH (2002 e 2009), criação da Secretaria Nacional de Direitos Humanos com status de ministério; e políticas sociais setorializadas (Adorno, 2000; Almeida, 2011; Silva, 2014). Atualmente, com o governo do presidente Bolsonaro há significativas mudanças neste cenário (Silva, 2020; Machado 2020).

\section{Movimentos e organizações de defesa dos direitos humanos}

Nos estudos sobre ativismo, movimentos e organizações de direitos humanos encontramos trabalhos que discutem o papel central da Igreja Católica contra a repressão política da ditadura militar e na articulação da pauta política e moral dos direitos humanos (Reis, 2012). Também encontramos estudos sobre a formação de movimentos locais, como o estudo de Pereira (2015), que analisou os movimentos de direitos humanos em São Luís (MA), e o de Tsunoda (2013), que realizou um estudo de caso da Comissão Teotônio Vilela. Destacamos, também, os textos de Ricoldi (2012), que analisa a organização não governamental Margarida Maria Alves em João Pessoa, na Paraíba. Soares (2014), Cardoso (2011); Cunha, 
Noronha, Vestena (2011) abordam o ativismo transnacional e a judicialização dos direitos humanos na Corte Interamericana de Direitos Humanos.

\section{O movimento anti direitos humanos no Brasil e no mundo}

Apesar do enorme esforço dos movimentos de direitos humanos em inaugurar uma nova cultura política e limpar o "entulho autoritário" (Pinheiro, 1991) que restava da ditadura nas leis, nas instituições e nos hábitos arraigados dos brasileiros, uma grande resistência à expansão desse imaginário político é sentida desde o início. Além das "falas" anti-direitos humanos (Caldeira, 2000). muitas práticas autoritárias permaneceram e se adaptaram à democracia (Pinheiro, 1991). A ação violenta dos agentes de Estado, por exemplo, mesmo ilegais e condenadas por tratados internacionais, são mantidas nas rotinas policiais sem efetivo questionamento. Esse fenômeno é compreendido por Pinheiro (1991) como expressão do "autoritarismo socialmente implantado", conceito que indica a existência de uma estrutura (cultural) brasileira que mantém certas práticas autoritárias independentemente da lei autorizar (legal ou ilegal), e do regime político (democracia ou ditadura). Essa dimensão político-cultural parece fundamental para mapear e compreender a extensão e complexidade da oposição aos direitos humanos hoje.

Existe uma literatura emergente sobre o fenômeno mais recente de oposição explícita, oficial e sistemática às leis, instituições e organizações da sociedade civil de direitos humanos. Vamos mencionar os que nos parecem mais ilustrativos desse enquadramento. Na Europa (Schneiker, 2018), em especial na Inglaterra (Wagner, 2014), nos Estados Unidos (Engle, 2016; Alston, 2017) e na América Latina (Krause, 2020) são observados movimentos importantes de oposição e contestação dos direitos humanos.

Em relação aos trabalhos que se debruçam sobre o fenômeno da oposição aos direitos humanos no Brasil na última década, Schettini (2016) propõe uma discussão teórica sobre o ódio que os direitos humanos despertam em determinadas esferas sociais. Propõe uma análise obre o papel do dissenso na política, sugerindo que o discurso dos direitos humanos tem um potencial de efetivamente produzir o dissenso, ao colocar dois ou mais mundos em contato.

Para a autora, o ódio declarado aos direitos humanos está diretamente ligado aos movimentos e discursos de resistência a determinadas configurações de poder. Ela aponta duas razões para o movimento: 1) os direitos humanos representam uma ferramenta disponível a qualquer um e 2) eles produzem uma autorização para subverter uma ordem social desigual endereçando algum tipo de concretização do princípio da igualdade (Schettini, 2016, p. 380). É importante lembrar, diz a autora, que não é qualquer oposição política que gera ódio, mas apenas aquela que é capaz de desorganizar as divisões do mundo sensível e perturbar a ordem normal de inteligibilidade dos acontecimentos.

Com a eleição de Jair Bolsonaro, em 2018, as políticas internas e internacionais de direitos humanos foram desconstituídas e revisadas. Silva (2020) analisou a situação dos burocratas que, ainda inseridos no serviço público federal, não compartilham da a maneira de pensar e implementar as políticas chamadas de direitos humanos do chefe do Executivo. Esses funcionários estão sendo alvo de perseguições e forçados a aderir a políticas internas e externas descoladas do que acreditam ser os valores dos direitos humanos (Silva, 2020). 
Machado (2020) analisou o que chama de recente movimentação neoconservadora no Congresso Nacional, liderada pelas frentes parlamentares que representam setores como a bancada evangélica e a agropecuária. De maneira geral, essas bancadas são refratárias a modalidades de direitos humanos, tais como a igualdade de gênero, a diversidade sexual, os direitos reprodutivos, assim como aos direitos indígenas e quilombolas à terra e o direito à proteção ambiental.

Para a autora, 2016 e 2017 foram anos que representaram uma mudança importante na maneira de se tratar publicamente dos direitos fundamentais. Durante esses anos, tornou-se possível atacar abertamente alguns direitos fundamentais, o que representa o enfraquecimento da hegemonia narrativa que direitos humanos. Diferente do antigo pensamento conservador brasileiro, que já havia saído um pouco de cena desde a redemocratização, a narrativa neoconservadora confronta diretamente a legitimidade da narrativa dos direitos humanos e a percepção do Estado como provedor de proteção social (Machado, 2020).

Uma das hipóteses que a autora levanta sobre esse período. e que nos parece bastante promissora. é que. dentre as condições de possibilidade para a consolidação da narrativa anti direitos humanos, as reações que sobrevieram ao lançamento do $3^{\circ} \mathrm{PNDH}$, em 2009, "tornou visível e promoveu a articulação das frentes parlamentares, desencadeando a formação de um movimento neoconservador que estava já entrincheirado no Congresso e enraizado em diversas bases eleitorais." (Machado, 2020, p.12, tradução nossa). Esse episódio parece ilustrar uma situação em que os dois movimentos históricos, de construção e desconstrução, invertem as posições e as intensidades das práticas.

\section{Conclusão}

Os direitos humanos têm sido objeto de intensa reflexão, especialmente na última década, por uma enorme variedade de pesquisadores e intelectuais de diversas áreas disciplinares. Esse texto é uma tentativa de dar sentido a essa produção, especialmente a produção brasileira e a literatura de língua inglesa (Estados Unidos e Canadá), buscando distinguir a literatura sócio-histórica da literatura normativa. Investimos nos trabalhos que se propuseram a fazer reflexões sobre os direitos humanos enquanto fenômeno social a ser observado. Também destacamos alguns trabalhos mais específicos sobre os temas que constituíram com mais expressividade o campo de pesquisa em direitos humanos no Brasil.

Ainda há muito a estudar sobre o fenômeno no Brasil, assim como o de sua oposição. Ambas são realidades sociais ainda pouco exploradas pelas ciências sociais, a despeito dos valiosos trabalhos já existentes. Sejam enquanto leis, princípios éticos, práticas, movimentos, ideologias, discursos, políticas públicas, cargos executivos ou missões oficiais, os direitos humanos ainda merecem muitos olhares curiosos e academicamente interessados.

Acompanhadas de outros autores, nossa intenção foi problematizar como a normatividade jurídica se tornou central na linguagem e na maneira de pensar dos direitos humanos e, paralelamente, como essa categoria de direitos se tornou auto explicativa e auto evidente nas práticas discursivas de acadêmicos, dos atores estatais e não estatais, da mídia, etc (López, 2018). A partir daí, pensamos ser tarefa urgente das ciências sociais interrogar sobre a eficácia do poder social 
dos direitos humanos para atender reivindicações empíricas concretas, situadas no tempo e no espaço histórico específicos. Isso, per si, não enfraquece, seus ideais normativos, convicções morais e a persuasão normativa. Pelo contrário, elas nos forçam a perguntar como as demandas empíricas em suas diversas formas (denúncia pública, prática política, discurso moral, racionalidade legal) integram a narrativa pública do imaginário político dos direitos humanos.

\section{REFERÊNCIAS BIBLIOGRÁFICAS:}

ABRÃO, Paulo; TORELLY, Marcelo. (2014), Mutações do conceito de anistia na justiça de transição brasileira: a terceira fase da luta pela anistia. In: PIOVESAN, Flávia; SOARES, Inês Virgínia Prado (orgs.). Direitos humanos atual. São Paulo: Elsevier.

ACHIUME, E. Tendayi. (2018), Pautando a igualdade racial na agenda global de direitos humanos. SUR - Revista Internacional de Direitos Humanos, 15, 28:141-150.

ADORNO, Sérgio. (2000), Insegurança versus direitos humanos entre a lei e a ordem.

Tempo Social - Revista de Sociologia da USP, 11, 2:129-153. Disponível: https:// doi.org/10.1590/S0103-20701999000200008, consultado em 20/10/2018.

(2010), História e desventura: o $3^{\circ}$ Programa Nacional de Direitos Humanos. Novos Estudos CEBRAP, 86, Disponível em https://doi.org/10.1590/S010133002010000100001, consultado em: 02/02/2017.

ALMADA, Pablo Emanuel Romero. (2021), O negacionismo na oposição de Jair Bolsonaro à Comissão Nacional da Verdade. Revista Brasileira de Ciências Sociais, 36 (106). Disponível em https://doi.org/10.1590/3610608/2021, consultado 05/01/2022.

ALMEIDA, Priscila Cabral. (2018), Processos de construção dos lugares de memória da resistência em Salvador - projetos, disputas e assimetrias. Tese de Doutorado. Fundação Getúlio Vargas, Rio de Janeiro.

ALMEIDA, Wellington Lourenço. (2011), A estratégia de políticas públicas em direitos humanos no Brasil no primeiro mandato Lula. Revista Katálysis, 14, 2:230-238. Disponivel: https://www.scielo.br/j/rk/a/LMpkgZcxkfcm7qNKDD7M7gp/abstract/?lang=pt, consultado em: 17/12/ 2021.

ALSTON, Philip. (2013), Does the past matter?: on the origins of human rights. Harvard Law Review, 126:2043-2081. Disponível em https://harvardlawreview. org/2013/05/does-the-past-matter-on-the-origins-of-human-rights/, consultado em 10/01/2022.

(2017), The populist challenge to human rights. Journal of Human Rights Practice, 9:1-15. Disponível em https://doi.org/10.1093/jhuman/hux007.Consultado em: 10/01/2022

ALVAREZ, Marcos; SALLA, Fernando; DIAS, Camila Nunes. (2013), Das Comissões de Solidariedade ao Primeiro Comando da Capital em São Paulo. Tempo Social Revista de sociologia da USP, 25 (1). Disponível: DOI: https://doi.org/10.1590/ S0103-20702013000100004, consultado em 15/12/2021.

ASTOLFI, Roberta C.; LAGATTA, Pedro. (2015), Os desafios para caracterizar o conceito de graves violações de direitos humanos a partir da análise dos julgamentos de 
deslocamento de competência de 2005 a 2014. I Revista Liberdades, 19. Disponível em https://ibccrim.org.br/publicacoes/exibir/461, consultada em 10/01/2022.

AZEVEDO, Desirée de Lemos (2016), "A única luta que se perde é a que se abandona": etnografia entre familiares de mortos e desaparecidos no Brasil. 2016. Tese de Doutorado. Universidade Estadual de Campinas, Campinas.

BARROS, Antonio Teixeira. (2020), O debate parlamentar sobre a Comissão Nacional da Verdade no Congresso Nacional brasileiro. Revista Brasileira de Ciências Sociais, 35 (104). Disponível em https://doi.org/10.1590/3510401/2020, Consultado 10/01/2022.

BERNARDES, Maria Nina. (2011), Sistema Interamericano de Direitos Humanos como esfera pública transnacional: aspectos jurídicos e políticos da implementação de decisões internacionais. SUR - Revista Internacional de Direitos Humanos, 8, 15:135-156. Disponível: https://core.ac.uk/download/pdf/16033946.pdf, consultado em 23/04/2021.

BISSET, Alison. (2013), Truth Commissions and Criminal Court. Cambridge, UK: Cambridge University Press.

BENHABIB, Seyla (2013). Moving beyond false binarisms: on Samuel Moyn's the last utopia. Qui Parle: critical humanities and social sciences, 22, 1:81-93.

BERNARDI, Bruno Boti. (2016), Justiça de transição e as leis de anistia da Corte Interamericana de Direitos Humanos. In: PIOVESAN, Flávia; SOARES, Inês Virgínia Prado. Impacto das decisões da Corte Interamericana de Direitos Humanos na jurisprudência do STF. Salvador: Juspodivm.

BLAU, Judith R.; MONCADA, Alberto. (2005), Human rights: Beyond the liberal vision. Lanham, MD and New York: Rowman \& Littlefield.

BLACKBURN, Robin. (2011), Reclaiming human rights. New Left Review, 69:126-138.

BOBBIO, Norberto (2004), A era dos direitos. Rio de Janeiro: Elsevier.

CALDAS, Caroline. (2016), Nada mais que a verdade? um mapeamento da experiência de justiça de transição brasileira. Dissertação de Mestrado. Universidade Federal Fluminense, Rio de Janeiro.

(2021), A justiça de transição e os direitos humanos: a persecução judicial pelo Ministério Público Federal dos crimes praticados no período da ditadura militar. Tese de Doutorado. Universidade Federal Fluminense, Niterói.

CALDEIRA, Teresa Pires do Rio. (2000), Cidade de Muros: crime, segregação e cidadania no Brasil. São Paulo: Edusp, Editora 34.

CARDOSO, Evorah. (2011), Ciclo de vida do litígio no Sistema Interamericano de Direitos Humanos: dificuldades e oportunidades para atores não estatais. Revista Electrónica del Instituto de Investigaciones Ambrosio L. Gioja. Disponível em http://bibliotecavirtual.cebrap.org.br/arquivos/272_artigo.pdf, consultado em 23/04/2021.

CARDIA, Nancy; POSSAS, Mariana T.; BLOTTA, Vítor; BASTOS, Lúcia E. A. F. (2014), A cobertura da mídia sobre a decisão da Corte interamericana de Direitos Humanos no caso Araguaia: promovendo mudanças ou mantendo a negação? In: 
PIOVESAN, Flávia; SOARES, Inês V. Prado (orgs.). Direitos humanos atual. Rio de Janeiro: Elsevier.

CASTRO, Giovane Michelon de. (2013), Direitos humanos e a política externa brasileira: um diálogo com o Sistema Interamericano. Dissertação de Mestrado. Universidade Federal do Rio Grande do Sul, Porto Alegre.

CAVALLO, Gonzalo Aguilar. (2018), Conhecimentos ecológicos indígenas e recursos naturais: a descolonização inacabada. Estudos Avançados, 32 (94). Disponível em https://doi.org/10.1590/s0103-40142018.3294.0024, consultado em 10/01/2022.

CLÉMENT, Dominique. (2017), Human rights or social justice? the problem of rights inflation, The International Journal of Human Rights, 22, 2: 1-15. Disponível em DOI: 10.1080/13642987.2017.1349245, consultado em 20/03/2019.

(2018), Debating rights inflation in Canada: a sociology of human rights, Waterloo, CA: Wilfried Laurier University Press.

COMPARATO, Fábio Konder (2010). A afirmação dos direitos humanos. São Paulo: Saraiva.

CUNHA, José Ricardo; NORONHA, Rodolfo; VESTENA, Carolina Alves. (2011). Judicialização da política e Sistema Interamericano de Direitos Humanos: uma investigação empírica da atuação das organizações da sociedade civil. Direito e Práxis, 2 (1). Disponível em DOI: https://doi.org/10.12957/dep.2011.2081, consultado em $21 / 06 / 2021$.

DÁVILA, Roberto Roja. (2018), Afrodescendentes como sujeitos de direitos do Direito Internacional dos Direitos Humanos: processo histórico de reconhecimento e desafios. SUR - Revista Internacional de Direitos Humanos, 15, 28:151-164. Disponível em: https://sur.conectas.org/wp-content/uploads/2019/05/sur-28-portugues-roberto-rojas-davila.pdf, consultado em: 22/02/2022.

EILBAUM, Lucía; MEDEIROS, Flavia. (2015). Quando existe 'violência policial'? Direitos, moralidades e ordem pública no Rio de Janeiro. Dilemas - Revista de Estudos de Conflito e Controle Social, 8(3), 407-428. Disponível em: https://revistas. ufr.br/index.php/dilemas/article/view/7299, consultado em 22/02/2022.

EILBAUM, Lucía; CHAGAS, Gisele F; MEDEIROS, Flavia. (2020). "Apresentação: Por Uma Abordagem etnográfica dos "direitos humanos": Conflitos, Moralidades e Direitos". Antropolítica - Revista Contemporânea De Antropologia, $n^{\circ} 47$ (janeiro). https://doi.org/10.22409/antropolitica2019.0i47.a42114, consultado em: 22/02/2022.

ENGELMANN, Fabiano; MADEIRA, Lígia Mori. (2015), A causa e as políticas de direitos humanos no Brasil. Caderno CRH, 28 ( 75).

ENGLE, Karen. (2016), "A Genealogy of the criminal turn in human rights". In: ENGLE, Karen; MILLER, Zinaida. Anti-impunity and the human rights agenda, Cambridge: Cambridge University Press.

ENGSTROM, Par. (2017), Reconceitualizando o impacto do Sistema Interamericano de Direitos Humanos. Revista Direito e Práxis, 2, 8:1250-1285. Disponível em https://www.scielo.br/j/rdp/a/pfd8drrwn3JM8ywBBFtFjzP/?lang=pt\&format= pdf, consultado em 25/05/ 2021. 
ENGSTROM, Par; (et al). Direitos Humanos (2008-2015). In: FLORENCIO, Sérgio (et al) (Org.). Política externa brasileira em debate: dimensões e estratégias de inserção internacional no pós-crise de 2008. Brasília: IPEA, 2018, p. 463-491.

FRANÇA, Fábio Gomes de. (2012). Segurança pública e a formação policial militar: os direitos humanos como estratégia de controle institucional. Estudos de Sociologia, 17 (33). Disponível em: https://periodicos.fclar.unesp.br/estudos/article/ view/5424, consultado em: 09/01/2022.

FERREIRA, Otavio Dias de Souza. (2019), Do Carandiru à lei antiterror: democratização e maré cinza na esfera pública sobre direitos humanos no sistema punitivo em São Paulo. Tese de Doutorado. Universidade de São Paulo, São Paulo.

FREIRE, Jussara. (2010), Agir no regime de desumanização: esboço de um modelo para análise da sociabilidade urbana na cidade do Rio de Janeiro. Dilemas Revista de Estudos de Conflito e Controle Social, 3, 10:119-142. Disponível em https://revistas.ufrj.br/index.php/dilemas/article/view/7186/19949, consultado em: 15/12/2018.

FREZZO, Mark. (2015), The sociology of human rights: an introduction. Cambridge. UK, Polity Press.

GUEDES, Íris Pereira; SCHÄFER, Gilberto; LARA, Leonardo Severo de. (2020) Territórios indígenas: repercussões do SIDH no Direito Brasileiro. Revista Direito e Práxis, 11 (01). Disponível em https://doi.org/10.1590/2179-8966/2019/34177, consultado em 10/01/2022.

HIGA, Gustavo Lucas e ALVAREZ, Marcos César. Humanização das prisões e pânicos morais: notas sobre as "Serpentes Negras".(2019) Estudos Avançados [online], v. 33, n. 96, pp. 69-90. Disponível em: <https://doi.org/10.1590/s01034014.2019.3396.0006>. Epub 12 Ago 2019. ISSN 1806-9592. https://doi. org/10.1590/s0103-4014.2019.3396.0006, consultado em: 22/02/2022.

HOLLANDA, C. Buarque de, \& ISRAEL, Vinícius Pinheiro (2019), Panorama das Comissões da Verdade no Brasil: uma reflexão sobre novos sentidos de legitimidade e representação democrática. Revista de Sociologia e Política, 27, 70:1-21. Disponível em https://revistas.ufpr.br/rsp/article/view/72818/40533, consultado em: 05/01/2022.

HOLLANDA, Cristina Buarque de. (2018), Direitos humanos e democracia: a experiência das comissões da verdade no Brasil. Revista Brasileira de Ciências Sociais, 33, 96:1-18. Disponível: https://www.scielo.br/j/rbcsoc/a/8PRcJPCwcY9VRRXbxMSkTzy/?format=pdf\&lang=pt, consultado em:05/01/2022

HOPGOOD, Stephen. (2013), The endtimes of human rights. New York: Cornell University Press.

(2014), Desafios para o regime global de direitos humanos: os direitos humanos ainda são uma linguagem eficaz para a mudança social? SUR - Revista Internacional de Direitos Humanos, 11, 20:71-80. Disponível em: https://sur.conectas.org/ desafios-para-o-regime-global-de-direitos-humanos/, consultado em 22/02/2022.

HYNES $P_{i}$ : LAMB M, SHORT $D_{i}$; WAITES M. (2011), Sociology and human rights: new engagements. London: Taylor and Francis. 
HUNT, Lynn. (2007), Inventing human rights: a history. New York: WW. Norton \& Company.

IGNATIEFF, M. (2001), Human rights as politics and idolatry, Princeton, New Jersey, EUA: Princeton University Press.

JOAS, Hans. (2012), A sacralidade da pessoa - nova genealogia dos direitos humanos. São Paulo: Editora da Universidade do Estado de São Paulo.

KOERNER, Andrei. (2003), O papel dos direitos humanos na política democrática: uma análise preliminar. Revista Brasileira de Ciências Sociais, 18, ( 56 ).

KRAUSE, Krystin. (2020), Authoritarianism, social dominance, and contesting human rights in Latin America. Latin American Research Review, 55, 2:254-265. Disponível em DOI: https://doi.org/10.25222/larr.113, consultado em 10/01/2022.

LAFER, Celso. (2014), Justiça, história, memória: reflexões sobre a Comissão da Verdade. In: PIOVESAN, Flávia; SOARES, Inês V. Prado. Direitos humanos atual. Rio de Janeiro: Elsevier.

LEMOS, C. B. (2020). Quem são os direitos humanos? Desconsideração e personificação em cadeias do Distrito Federal. Antropolítica - Revista Contemporânea De Antropologia, (47). https://doi.org/10.22409/antropolitica2019.0i47.a42023， consultado em 22/02/2022.

LÓPEZ, José Jullian.(2018), Human rights as political imaginary. Palgrave Macmillan.

MACHADO, Lia Zanotta. (2020), From the time of rights to the time of intolerance the neoconservative movement and the impact of the Bolsonaro government. Challenges for brazilian anthropology. Vibrant: Virtual Brazilian Anthropology, 17. Disponível em https://doi.org/10.1590/1809-43412020v17d458, consultado em 29/12/2021.

MADSEN, Mikael; VERSCHRAEGEN, Gert. (2013), Making human rights intelligible: towards a sociology of human rights. Oxford: Hart.

MAGALHÃES, Juliana N. (2013), A formação do conceito dos direitos humanos. Curitiba: Juruá Editora.

MECKLED-GARCÍA, Saladin; BASAK, Çali (Orgs.). (2005), The legalization of human rights: multidisciplinary perspectives on human rights and human rights law. New York: Routledge.

MEZAROBBA, Glenda. (2010), Entre reparações, meias verdades e impunidade: o difícil rompimento com o legado da ditadura no Brasil. SUR - Revista Internacional de Direitos Humanos, 7, 13:7-25. Disponível em: https://sur.conectas.org/wpcontent/uploads/2017/11/sur13-port-completa.pdf, consultado em: 22/02/2022.

MEYER, Emílio P. N. Anistia e poder constituinte: base para uma compreensão hermenêutica do projeto constitucional instituído pela Constituição de 1988. In: PIOVESAN, Flávia; SOARES, Inês V. Prado. Direitos humanos atual. Rio de Janeiro: Elsevier.

MORRIS, Lydia.(2006), Rights: sociological perspectives. Abingdon, Oxon: Routledge.

MOYN, Samuel. (2010), The last utopia. Cambridge, USA: The Belknap Press of Harvard University Press. 
(2014), O futuro dos direitos humanos, SUR - Revista Internacional de Direitos Humanos, 11, 20:61-69. Disponível em: https://sur.conectas.org/o-futurodos-direitos-humanos/, consultado em: 22/02/2022. phia, EUA.

(2015), Christian human rights. University of Pennsylvania Press, Philadel-

(2018), Not enough: Human Rights in an unequal world. Cambridge, Massachusetts: Harvard University press.

(2021), Direitos humanos e usos da história. Trad. Beth V. Honorato. São Paulo: UNIFESP. (e-book).

MORGAN, Rhiannom. (2009), Human rights research and the social sciences. In: MORGAN, Rhiannom; TURNER, Bryan (eds). Interpreting human rights: social science perspective. London and New York: Routledge.

NASCIMENTO, Bruno Fontes do. (2019), As políticas públicas de segurança e o paradoxo dos direitos humanos: uma análise sociopolítica das políticas de segurança pública no Brasil e do ensino policial na Academia Estadual de Polícia Civil do Rio de Janeiro. Dissertação de Mestrado. Universidade Federal do Rio de Janeiro, Rio de Janeiro.

OLIVEIRA, Vanessa Veiga de. (2014), Desafios para o avanço dos direitos humanos no Brasil: uma análise das justificações no debate mediado em torno do caso do PNDH-3. In: Revista Compolítica, 4, 2:156-184. Disponível em https://doi. org/10.21878/compolitica.2014.4.2.72, consultada em 04/01/2022.

PEREIRA, A. (2014), Brazil's Truth Commission: opportunities and risks. In: PIOVESAN, Flávia; SOARES, Inês V. Prado (Orgs.). Direitos Humanos Atual, São Paulo, Elsevier Editora.

PEREIRA, Jesus Marmanillo. (2015), Luta por direitos: movimentos sociais de direitos humanos em São Luís durante a década de 1980. Tese de Doutorado. Universidade Federal da Paraíba, João Pessoa.

PINHEIRO, Márcia Leitão. (2018), Uma Comissão da Verdade no Brasil: escravidão, multiculturalismo, história e memória. Civitas - Revista de Ciências Sociais, 18 3:683-688. Disponível em https://doi.org/10.15448/1984-7289.2018.3.26160, consultado 05/01/2022.

PINHEIRO, Paulo Sérgio (1991). Autoritarismo e transição. Revista da USP. Disponível em https://doi.org/10.11606/issn.2316-9036.v0i9p45-56, consultado em 20/03/2017.

PIOVESAN, Flávia; SOARES, Inês V. Prado. (2016), Impactos das decisões da Corte Interamericana de Direitos Humanos na jurisprudência do STF. Salvador: JusPODIVN.

PIRES, Thula. (2018), Racializando o debate sobre direitos humanos. SUR - Revista Internacional de Direitos Humanos, 15, 28:65-75. Disponível em: https://sur. conectas.org/wp-content/uploads/2019/05/sur-28-portugues-thula-pires.pdf, consultado em: 22/02/2022

POSSAS, Mariana Thorstensen; RAMOS, Núbia dos Reis; ALMEIDA, Lorena Sales de. (2018), "Os direitos humanos como discurso de enquadramento: uma análise sociológica da mobilização dos direitos humanos por organizações não governa- 
mentais e o tribunal interamericano". In: MARQUES, Verônica Teixeira; LEAL, Maria Lúcia Pinto; ZIMMERMMANN, Clóvis (orgs.). Direitos humanos na democracia contemporânea: velhos e novos embates. Rio de Janeiro: Bonecker. (e-book).

POSSAS, Mariana Thorstensen. (2016), Da sociologia com os direitos humanos para a sociologia dos direitos humanos. In: BARREIRA, César; PAIVA, Luiz F. S. ; RUSSO, Maurício B. (Orgs.). Violência, territorialidades e negociações. Campinas: Pontes, 2016, p. 45-65.

POSSAS, Mariana Thorstensen; CARVALHO, Denise; ASTOFOLI, Roberta; MONTEIRO, Silvana. (2012), Monitoramento de violações dos direitos humanos e o problema da seleção de direitos: reflexões sobre os limites da teoria dos direitos humanos.

Contemporânea, 2, 1: 103-127. Disponível em www.contemporanea.ufscar.br/ index.php/contemporanea/article/view/62/35, consultado em 28/10/2016.

POSSAS, Mariana Thorstensen; ALVAREZ, M; HOLANDA, C. Buarque de. (2020). Projeto de pesquisa - História dos direitos humanos no Brasil. Universidade Federal da Bahia, 2020, Salvador, Bahia[Documento não publicado].

RAMANZINI, Isabela Gerbelli Garbin. (2018), Impactos da justiça transicional sulamericana no Sistema Interamericano de direitos humanos. Lua Nova, 103. Disponível em https://doi.org/10.1590/0102-126/103, consultado em 10/01/2022.

REIS, Rossana Rocha. (2012), O direito à terra como um direito humano: a luta pela reforma agrária e o movimento de direitos humanos no Brasil. Lua Nova, 86:89122. Disponível em https://doi.org/10.1590/S0102-64452012000200004, consultado em: 12/09/2012.

RIBEIRO, Gustavo Lins. (2003), Cultura, direitos humanos e poder: mais além do império e dos direitos humanos: por um universalismo heteroglóssico. Série Antropologia. Brasília, 340:1-16. Disponível em https://repositorio.unb.br/ handle/10482/17677, consultado em: 09/01/2022.

RICOLDI, Arlene Martinez. (2012), Temas em direitos humanos de uma organização da Paraíba e o master frames de direitos humanos. Lua Nova, 86: 123-154. Disponível em: https://doi.org/10.1590/S0102-64452012000200005, consultado em 07/01/2022.

RIFIOTIS, Theophilos. (2014). Judicialização dos direitos humanos, lutas por reconhecimento e políticas públicas no Brasil: configurações de sujeito. Revista de Antropologia. 57, 1:119-144. Disponível em https://doi.org/10.11606/2179-0892. ra.2014.87755, consultado em: 11/01/2022.

RIOS, Roger Raupp; RESADORI, Alice Hertzog; LEIVAS, Paulo Gilberto Cogo; SCHAFER, Gilberto. (2017). O Sistema Interamericano de Direitos Humanos e a discriminação contra pessoas LGBTTI: panorama, potencialidade e limites. Revista Direito e Práxis, 8 (2). Disponível em https://doi.org/10.12957/dep.2017.28033, consultado em 10/01/2022.

RORIZ, João Henrique. (2018), Direitos humanos como um novo projeto para o Direito Internacional? notas sobre The Last Utopia, de Samuel Moyn. Revista de Direito Internacional, 15, 2:490-496. Disponível em https://www.publicacoes. uniceub.br/rdi/article/view/5489/4002, consultado em 10/01/2022. 
(2017), Clashing frames: human rights and foreign policy in the Brazilian re-democratization process. Revista Brasileira de Política Internacional, 60 (1). Disponível em https://doi.org/10.1590/0034-73292017001020, consultado em 10/12/2021.

ROSA, Marlise. (2016), O uso estratégico dos direitos humanos para a criminalização da alteridade: a Lei Muwaji e a campanha contra o infanticídio indígena no Congresso Nacional. In: FONSECA, Cláudia [et. al.] (Orgs,) Antropologia e direitos humanos. Rio de Janeiro: Mórula.

SANDOVAL, Carlos Arturo Villagrán; VEÇOSO, Fabia Fernandes Carvalho. (2017), A human rights' - tale of competing narratives. Revista Direito e Práxis, 8, (2). Disponível em www.scielo.br/j/rdp/a/WJdbj5pFVCNQ7VXR5jhsmYr/?format= pdf\&lang=en, consultado 13/10/2021.

SANJURJO, Liliana. (2013), Sangue, identidade e verdade: memórias sobre o passado ditatorial na Argentina. Tese de Doutorado. Universidade Estadual de Campinas, São Paulo.

SANTOS, Flávia Medeiros. (2017), "De criminosa a vítima": abortos, polícia e direitos humanos na região metropolitana do Rio de Janeiro. In: EILBAUM, Lucía; SCHUCH, Patrice; CHAGAS, Gisele F (orgs.). Antropologia e direitos humanos 7. Rio de Janeiro: Associação Brasileira de Antropologia.

SCHALLENMÜLLER, Christian Jecov (2015). O discurso da "conciliação nacional" e a justiça de transição no Brasil. Tese de Doutorado. Universidade de São Paulo, São Paulo.

SCHETTINI, Andrea Bandeira de Mello. (2016), O ódio aos direitos humanos. In: COUTINHO, Ana Luísa Celino; ROCHA, Leonel Severo, ALVIM, Marcia Cristina de Souza (orgs.). Filosofia do Direito I. Florianópolis: CONPEDI.

SCHNEIKER, Andrea. (2018), The new defenders of human rights? how radical right-wing TNGOs are using the human rights discourse to promote their ideas. Global Society. Disponível em DOI: 10.1080/13600826.2018.1546673, consultado 10.01.2022.

SCHRITZMEYER, Ana Lúcia Pastore. (2018), Direitos Humanos e suas circulações extra-legais: algumas reflexões antropológicas. Ponto Urbe, 23. Disponível em http://journals.openedition.org/pontourbe/5052, consultado em 10/12/2021.

SILVA FILHO, José C. M. da. (2014), A ambiguidade da anistia no Brasil: memória e esquecimento na transição inacabada. In: PIOVESAN, Flávia; SOARES, Inês V. Prado (orgs.). Direitos humanos atual. Rio de Janeiro: Elsevier.

SILVA, Michelle Morais de Sá e. (2020), Once upon a time, a human rights ally: the state and its bureaucracy in right-wing populist Brazil. Human Rights Quarterly, 42:46-666. Disponível em https://muse.jhu.edu/article/761352/pdf, consultado em 10/01/2022.

SILVA, Kelly. (2014), Da resistência à violência de Estado a um novo projeto de formação nacional: genealogias das políticas de direitos humanos no Brasil. In: Anuário Antropológico, l:1-19. Disponível em http//:aa.revues.org/638, consultado em 19/04/2020. 
SILVA, Naiara Alves da. (2017), Uma história da ideia de direitos humanos no Brasil a partir dos bispos católicos da CNBB (1952 - 1989). Tese de Doutorado, Universidade Federal Fluminense, Niterói.

SIKKINK, Kathryn. (2011), The justice cascade: how human rights prosecutions are changing world politics. New York, NY: W.W. Norton \& Company.

SIMONI, Mariana Yokoya. (2016), Justiça em transição no Brasil: anistia política e reparação dos militantes da Guerrilha do Araguaia. Jundiaí: Paco Editorial.

SINGER, Helena. (2003). Discursos desconcertados. Linchamento, punições e direitos humanos. São Paulo: Humanitas, FFLCH/USP, FAPESP.

SJOBERG, Gideon; GILL, Elizabeth A.; WILLIAMS, Norma. (2001), A Sociology of human rights. Social Problems, 48 (1).

SOARES, Marcos Caprio Fonseca. (2014), Direitos Humanos e ativismo transnacional: o Brasil na Corte Interamericana - estudo de caso. Tese de Doutorado. Universidade Federal do Rio Grande do Sul, Porto Alegre.

SOMERS, Margaret; ROBERTS, Christopher. (2008), Towards a new Sociology of rights: a genealogy of "buried bodies" of citizenship and human rights. Annual Review of Law and Social Science, 4:385-425. Disponível em www.academia. edu/29983291/_Toward_a_New_Sociology_of_Rights_A_Genealogy_of_Buried_ Bodies_of_Citizenship_and_Human_Rights_, consultado em 04/01/2022.

SOUSA, Rosinaldo Silva de. (2001), Direitos humanos através da história recente de uma perspectiva antropológica. In: NOVAES, Regina Reyes; LIMA, Roberto Kant de. (Orgs.) , Antropologia e direitos humanos - Prêmio ABA/FORD. Niterói: EdUFF.

TEITEL, Ruti. (2011), "Transitional Justice Genealogy". In: REÁTEGUI, F. (Org.). Transitional justice: handbook for Latin America. Brasília: Comissão de Anistia, Ministério da Justiça; New York, International Center for Transitional Justice.

TRINDADE, Antônio Augusto Cançado (2000), A proteção internacional dos direitos humanos e o Brasil. $2^{a}$ ed. Brasília: UNB,

TSUNODA, Fabio Silva. (2013), Comissão Teotônio Vilela (CTV): direitos humanos e vocação militante. Dissertação de Mestrado. Universidade de São Paulo, São Paulo.

TURNER, Bryan S. (2006). Vulnerability and human rights. University Park: Penn. State Univ. Press.

(1993) Outline of a theory of human rights. Sociology, 27, 3:489-512. Disponível em https://www.jstor.org/stable/42855235, consultado 05/12/2022.

VENTURI, Gustavo. ( 2010), Direitos humanos: percepções da opinião pública. Brasília: Secretaria de Direitos Humanos.

WAGNER, Adam.(2014), The Mostering of human rights, Conference on Human Rights in the UK Media: Representations and Reality. Dispnivel em: https://adam1 cor.files.wordpress.com/2014/09/the-monstering-of-human-rights-adam-wagner-2014.pdf (Acesso em 08 de fev.2022)

WOJCIECHOWSKI, Paola Bianchi. (2014), O impacto do Sistema Interamericano de Proteção dos Direitos Humanos e dos ditames da justiça transicional na interpre- 
tação e aplicação da lei de anistia brasileira: a fragilização do estado democrático de direitos frente à denegação do direito à justiça. In: PIOVESAN, Flávia; SOARES, Inês V. Prado (Orgs.). Direitos humanos atual. Rio de Janeiro: Elsevier.

WOODIWISS, Anthony. (2005a), The law cannot be enough. In: MECKLED-GARCÍA, Saladin; BASAK, Çali (eds). The legalization of human rights: multidisciplinary perspectives on human rights and human rights law. New York: Routledge.

(2005b), Human Rights. Abingdon, Oxon: Routledge. 


\section{Resumo}

\section{Direitos humanos em balanço: enquadramentos teóricos e recorte empíricos}

Os direitos humanos têm sido objeto de intensa reflexão, especialmente na última década, por uma enorme variedade de pesquisadores e intelectuais de diferentes áreas disciplinares. Esse texto é uma tentativa de dar algum sentido a essa produção, com foco no Brasil e na literatura internacional de língua inglesa (Estados Unidos/Canadá), buscando distinguir a literatura sócio-histórica da literatura normativa, tanto jurídica quanto de cunho político-filosófico. Especial atenção foi dedicada aos trabalhos que se propuseram a fazer alguma reflexão sobre o próprio objeto dos direitos humanos, enquanto fenômeno empírico a ser observado.

Palavras-chave: direitos humanos, sociologia dos direitos humanos, história dos direitos humanos, imaginário político.

\section{Abstract \\ Human rights in balance: theoretical frameworks and empirical researches}

Human rights have been the subject of intense reflection, especially in the last decade, by a wide variety of researchers and intellectuals from different disciplinary areas. This text is an attempt to give some meaning to this production, focusing on Brazil and in international English language literature (United States/Canada), seeking to distinguish socio-historical literature from normative literature, both legal and political-philosophical. We paid special attention to works that proposed to reflect on the very object of human rights, as an empirical phenomenon to be observed.

Keywords: human rights, sociology of human rights, history of human rights, political imagination. 